\title{
Effect of Surface Treatment of Multi-Directionally Forged (MDF) Titanium Implant on Bone Response
}

\author{
Ginga Suzuki ${ }^{1, *}$, Masatsugu Hirota ${ }^{2}$, Noriyuki Hoshi ${ }^{3}$, Katsuhiko Kimoto ${ }^{3}$, Hiromi Miura ${ }^{4}$, \\ Masao Yoshinari ${ }^{5}$, Tohru Hayakawa ${ }^{2}$ and Chikahiro Ohkubo ${ }^{1}$ \\ 1 Department of Removable Prosthodontics, Tsurumi University School of Dental Medicine, 2-1-3 Tsurumi, \\ Tsurumi-ku, Yokohama 230-8501, Japan; okubo-c@tsurumi-u.ac.jp \\ 2 Department of Dental Engineering, Tsurumi University School of Dental Medicine, 2-1-3 Tsurumi, \\ Tsurumi-ku, Yokohama 230-8501, Japan; hirota-masatsugu@tsurumi-u.ac.jp (M.H.); \\ hayakawa-t@tsurumi-u.ac.jp (T.H.) \\ 3 Department of Oral Interdisciplinary Medicine, Prosthodontics \& Oral Implantology, \\ Graduate School of Dentistry, Kanagawa Dental University, 82 Inaoka-cho, Yokosuka, \\ Kanagawa 238-8580, Japan; hoshi@kdu.ac.jp (N.H.); k.kimoto@kdu.ac.jp (K.K.) \\ 4 Department of Mechanical Engineering, Toyohashi University of Technology, 1-1 Hibarigaoka, \\ Tempaku-cho, Toyohashi, Aichi 441-8580, Japan; miura@me.tut.ac.jp \\ 5 Oral Health Science Center, Tokyo Dental College, 2-9-18 Misaki-cho, Chiyoda-ku, Tokyo 101-0061, Japan; \\ yosinari@tdc.ac.jp \\ * Correspondence: 2711007@stu.tsurumi-u.ac.jp; Tel.: +81-45-580-8420
}

Received: 10 January 2019; Accepted: 10 February 2019; Published: 14 February 2019

\begin{abstract}
Multi-directional forging (MDFing) of titanium drastically improved its mechanical properties due to the evolution of an ultrafine-grained structure. Forging strain was repeatedly applied while changing the forging axis during MDFing. Of note is the decreased elastic modulus of MDFed titanium (MDF-Ti) as compared to conventional coarse-grained pure $\mathrm{Ti}$ (Ti). In the present study, we evaluated bone's response toward surface-treated MDF-Ti after implantation into the extraction sockets of rat maxillary molars. As surface treatments, acid (Acid, sulfuric acid at $120{ }^{\circ} \mathrm{C}$ for $75 \mathrm{~s}$ ), alkali without post-heat (Alkali, $\mathrm{NaOH}$ at $60^{\circ} \mathrm{C}$ for $24 \mathrm{~h}$ ), and alkali with post-heat (Alkali-heat, subsequent heating at $600{ }^{\circ} \mathrm{C}$ for $1 \mathrm{~h}$ ) treatments were employed. The presence of minute nanoscale dimples in the microscale dimples to form regular fractal structures on MDF-Ti surfaces was observed after Acid treatments. Structures of sponge-like porous networks after Alkali treatments and submicron fiber networks after Alkali-heat treatment were produced on the surfaces of both Ti and MDF-Ti. Surface-treated specimens were superhydrophilic. More crystal deposition was clearly observed on each surface-treated specimen after immersion in simulated body fluid for both Ti and MDF-Ti. The bone-to-implant contact (BIC) ratios of the Acid and Alkali-heat specimens were significantly higher than those of the untreated control $(p<0.05)$. Moreover, Acid and Alkali-heat treatment for MDF-Ti caused significantly greater BICs than that for Ti $(p<0.05)$. In conclusion, Acid or Alkali-heat treatment of MDF-Ti is useful for improving bone response.
\end{abstract}

Keywords: multi-directional forging; ultrafine grain; titanium implant; sulfuric acid; alkali and heat treatment

\section{Introduction}

Commercially pure titanium (Ti) and Ti alloys have commonly been used as dental implants due to their superior biocompatibility, especially tight bone bonding, which is commonly known as osseointegration [1]. As Ti alloys, Ti-6Al-4V and Ti-6Al-7Nb were used because their mechanical properties were superior to those of Ti. However, some problems, which must be solved, still exist for Ti 
alloy dental implant materials. One is that the released heavy metal ions from Ti alloys bring biological risks such as cancer with vanadium and Alzheimer's disease with aluminum [2,3]. Thus, new Ti alloys, such as Ti-Nb-Ta-Zr, Ti-Nb-Sn, or Ti-Mn alloy, without harmful vanadium and aluminum, have been developed [4-7].

The difference in elastic moduli between Ti alloys and bone is another serious problem. The elastic modulus of cortical bone was reported to be approximately 10-30 GPa, and that of Ti alloys such as Ti-6Al-4V was approximately $110 \mathrm{GPa}$ [4]. These differences in elastic moduli can cause the uneven transmission of applied stress at the interface between bone and implant materials, which is called stress shielding. This uneven loading sometimes results in the loosening and/or fracture of titanium implants [8,9]. Sumitomo et al. investigated the healing of experimental fractures made in rabbit tibiae by bone plates with different elastic moduli and confirmed that elastic moduli of bone plates will naturally influence the bone tissue reaction to the bone plate fixation [10]. They suggested that $\mathrm{Ti}$ alloy with low rigidity is a promising and applicable metallic biomaterial that provides a new option for fracture fixation. Some reported the development of the beta type titanium alloy with decreased elastic modulus [11-14]. The elastic modulus of beta-type titanium alloy was approximately below $80 \mathrm{GPa}$. However, the ultimate tensile strengths of the beta-type titanium alloy are less than $1 \mathrm{GPa}$. For example, the ultimate tensile strength of Ti-19Nb-13-Ta0-4.6Zr is approximately $800 \mathrm{MPa}$ [10].

On the contrary, a decrease in grain size $(d)$ can induce strengthening of the metallic materials without adding any alloying elements, which is known as the Hall-Petch relation [14,15]. Because ultrafine-grained structures $(d \leq 1 \mu \mathrm{m})$ exhibit marvelous properties, methods for developing ultrafine-grained structures are now matters of interest and study. The most powerful method of achieving ultrafine-grained structure is the severe plastic deformation (SPD) method. The SPD method is a newly developed method for the large plastic deformation of metallic materials to giant strain regions of more than a few hundred percent. Accumulative roll bonding (ARB) [16], high-pressure torsion (HPT) [17], equal-channel angular pressing (ECAP) [18], and multi-directional forging (MDF) $[19,20]$ are known as the SPD method. Applications of HPT or ECPA to titanium or titanium alloy were reported [13,21-23]. However, these HPT or ECPA methods were carried out at elevated temperatures for enhancing slip deformation. Miura et al. successfully applied the MDF method to $\mathrm{Ti}$ at room temperature and reported ultrafine-grained structures and remarkably higher tensile strengths [24]. Multi-directional forging is also useful method for preparing large samples, and there is little limitation of the shape. As illustrated in Figure 1, forging strain was repeatedly applied while changing the forging axis during MDF Miura et al. successfully applied the MDF method to Ti or magnesium alloys and reported ultrafine-grained structures and remarkably higher tensile strengths [17-19]. The average grain size of conventional $\mathrm{Ti}$ is approximately $30 \mu \mathrm{m}$, whereas that of MDF pure Ti grade 2 (MDF-Ti) is finer than $100 \mathrm{~nm}$ [24]. The ultimate tensile strength of MDF-Ti is more than $1 \mathrm{GPa}$, and that of grade $2 \mathrm{Ti}$ was approximately 350-500 MPa. MDF improved the ultimate tensile strength more than twice (almost twice). The notable points of MDF-Ti are not only the increased tensile strength and/or hardness but also the decreased elastic modulus as compared to conventional pure Ti [25]. The elastic modulus of MDF-Ti was approximately 50 GPa. The lower elastic modulus of MDF-Ti achieved is an attractive property for a dental implant material. Varieties of surface modification of titanium dental implants, such as sand-blasting, acid or alkaline treatment, hydroxyapatite coating, and protein immobilization have been reported to improve bone response [26-30]. Large grid sandblasting and acid etching (SLA) treatment, which is commonly applied on commercially available titanium dental implants, produced nano-scale roughened surface in the micro- or macro- roughened surface [31]. Immersion of SLA surface in a saline solution produced a hydrophilic surface, resulting in better bone bonding to titanium implants [32]. Wettability is also another factor for influencing tissue response [33]. 


\section{Compression strain}
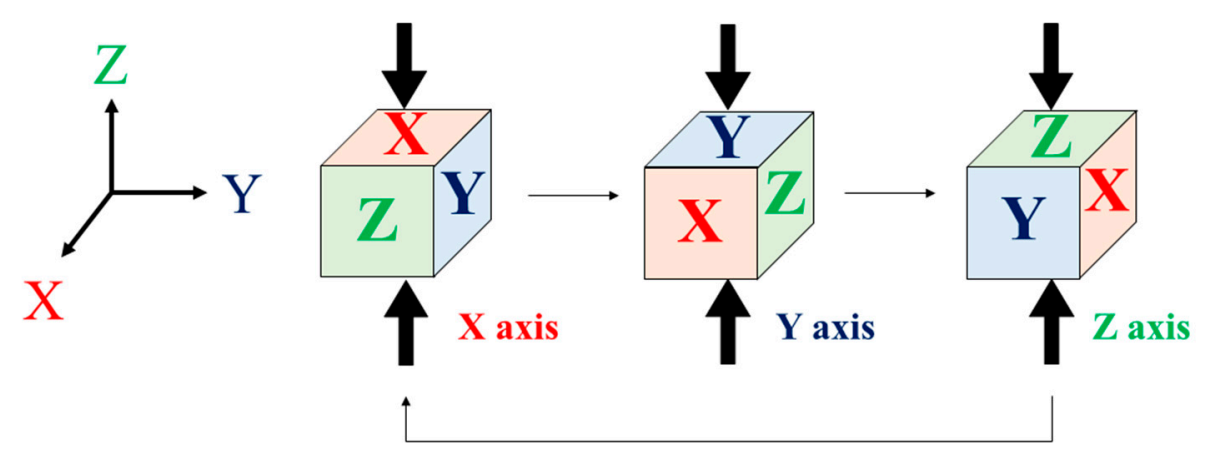

Figure 1. Schematic illustration of the multi-directional forging (MDF) method. The forging direction was changed by 90 degrees pass by pass.

Most of the commercially available dental Ti implants were surface modified for getting tight bonding to bone. Surface modification which can improve bone compatibility should be needed to apply Ti with ultrafine-grained structure in dental clinics. A few reported sandblasting, acid etching, and alkali treatment to ECAP-processed Ti [34,35]. Regarding MDF-Ti, Suzuki et al. reported that as-machined and sandblasted MDF-Ti showed a bone response similar to that of sandblasted Ti after implantation into the cortical bones of rabbit tibiae [36]. Arai et al. reported that sulfuric acid treatment of MDF-Ti produced minute nanoscale dimples in the macroscale dimples, i.e., fractal structure, and promoted the proliferation of osteoblast-like cells on MDF-Ti more significantly than on conventional $\mathrm{Ti}$ [37]. In addition to acid treatment, alkali and heat treatment of Ti is also a well-known method for providing strong bone-bonding ability [38-41]. Acid or alkali treatment is a simple method without any special techniques and any expensive apparatus. No attempts of alkali and heat treatment of MDF-Ti were reported.

In the present study, we evaluated the bone response toward surface-modified MDF-Ti after implantation into the extraction sockets of rat maxillary molars. Evaluation of bone response should be needed for checking the possibility of MDF-Ti for the application as a dental implant. The difference of grain size is expected to produce different surface morphology after surface modification. It will be elucidated that different surface morphologies will influence the bone response in animal experiments. Both acid and alkali treatment were performed on MDF-Ti implants. In the case of alkali treatment, two methods, namely with and without post-heat treatment, were employed, and the influence of post-heat treatment on tissue response was also evaluated.

\section{Materials and Methods}

\subsection{Titanium Specimens}

Disk and screw-type substrates were employed in the present study. A commercially pure Ti disk ( $\Phi 15 \mathrm{~mm} \times 1.0 \mathrm{~mm}$; JIS 2 type; 99.9\% mass; Furuuchi Chemical Corp., Tokyo, Japan) and an MDF-Ti disk ( $\Phi 15 \mathrm{~mm} \times 1.0 \mathrm{~mm}$; JIS 2 type; 99.9\% mass; Kawamoto Heavy Industries Co., Ltd., Takasago, Hyogo, Japan) were used to measure contact angles toward double-distilled water and immersion experiments in simulated body fluid (SBF). Both disks were polished with \#800 and \#1200 waterproof paper and ultrasonically cleaned in distilled water, ethanol, and double-distilled water for $15 \mathrm{~min}$. After cleaning, they were stored in a desiccator overnight.

Screw-type pure Ti implants ( $\Phi 1.5 \mathrm{~mm} \times 3.0 \mathrm{~mm}$; JIS 2 type; $99.9 \%$ mass; Kawamoto Heavy Industries Co., Ltd., Takasago, Hyogo, Japan) and MDF-Ti implants ( $\Phi 1.5 \mathrm{~mm} \times 3.0 \mathrm{~mm}$; JIS 2 type; 99.9\% mass; Kawamoto Heavy Industries Co., Ltd., Takasago, Hyogo, Japan) were used to measure the surface roughness and animal implantation experiments. Those implants were prepared for rat study. 
Similar to disk specimens, screw-type implants were ultrasonically cleaned in distilled water, ethanol, and double-distilled water for $15 \mathrm{~min}$. After cleaning, they were stored in a desiccator overnight.

\subsection{Surface Treatment}

Acid (Acid), alkali without post-heat treatments (Alkali), and alkali with post-heat treatment (Alkali-heat) were applied in our laboratory. For Acid treatment, Ti and MDF-Ti samples were immersed in $21 \mathrm{~mL}$ of 68 mass\% sulfuric acid at $120^{\circ} \mathrm{C}$ for $75 \mathrm{~s} \mathrm{[37].} \mathrm{For} \mathrm{Alkali} \mathrm{and} \mathrm{Alkali-heat}$ treatments, Ti and MDF-Ti samples were soaked in $20 \mathrm{~mL}$ of $5 \mathrm{M} \mathrm{NaOH}$ solution at $60^{\circ} \mathrm{C}$ for $24 \mathrm{~h}$. Alkali-heat samples were prepared by subsequent heat treatment at $600{ }^{\circ} \mathrm{C}$ for $1 \mathrm{~h}[38,39]$. After each surface treatment, treated substrates were washed twice with double-distilled water for $30 \mathrm{~s}$ and twice with methanol (Special grade, Wako Pure Chemical Industries, Ltd., Osaka, Japan) for $30 \mathrm{~s}$, followed by blow-drying for $30 \mathrm{~s}$. After each treatment, the surfaces were observed by scanning electron microscopy (SEM, JSM5600LV, JEOL Ltd., Tokyo, Japan) at an accelerating voltage of $15 \mathrm{kV}$. Before SEM observation, each specimen was sputter coated with gold. The surfaces of untreated Ti and MDF-Ti substrates were also observed as controls.

\subsection{Surface Roughness Measurements}

After each surface treatment, the surface roughness of Ti and MDF-Ti screw-type implants was measured using a shape analyzer laser microscope (VK-X250, KEYENCE Corp., Osaka, Japan). The valley parts of implants were measured. Size of acquired images were $10 \times 10 \mu \mathrm{m}^{2}$. For evaluating surface roughness of dental implants, 3-dimensional measurements should be preferably performed [42]. Thus, two surface parameters, the three-dimensional arithmetic mean height (Sa) and the developed interfacial area ratio (surface deployment area rate) (Sdr), were obtained. The Sa and Sdr of untreated control samples were also obtained. Sa is the arithmetic average of the absolute value of the surface height deviation measured from the best fitting and Sdr is the developed area due to the surface texture versus an ideal plane area ratio. Sa and Sdr are calculated according to the following equation.

$$
\begin{gathered}
\text { Sa }=\frac{1}{A} \iint_{A}|Z(x, y)| d x d y \\
\mathrm{Sdr}=\frac{1}{A}\left[\iint_{A}\left(\sqrt{\left[1+\left(\frac{\partial z(x, y)}{\partial x}\right)^{2}+\left(\frac{\partial z(x, y)}{\partial y}\right)^{2}\right]}-1\right) d x d y\right]
\end{gathered}
$$

\subsection{Contact Angle Measurements}

The contact angles of untreated (control) and surface-treated disks versus double-distilled water were measured using a contact angle meter (DMe-201, Kyowa Interface Science Co., Ltd., Tokyo, Japan). The water drop volume was maintained at $1.5 \mu \mathrm{L}$, and three measurements of $15 \mathrm{~s}$ each were made for each surface. The conditions of the measurements were maintained at the same room temperature $\left(25 \pm 1^{\circ} \mathrm{C}\right)$ and humidity $(45 \pm 1 \%)$.

\subsection{Simulated Body Fluid (SBF) Immersion}

Hanks' Balanced Salt Solution (HBSS) without organic species was used as the SBF [43]. The concentrations of each ion in HBSS are listed in Table 1. The pH of HBSS was adjusted to 7.4. Untreated control and surface-treated disks were immersed in $20 \mathrm{~mL}$ of $\mathrm{HBSS}$ at $37{ }^{\circ} \mathrm{C}$ in a polypropylene bottle for 1 day. After immersion, the disks were removed from HBSS and were rinsed with double-distilled water. After rinsing, the disks were immediately dried in a desiccator. The surface appearances of each disk after immersion in HBSS were observed using SEM at an accelerating voltage of $15 \mathrm{kV}$. Before SEM observation, each specimen was sputter coated with gold. 
Table 1. Concentrations of electrolytes in Hanks' Balanced Salt Solution (HBSS).

\begin{tabular}{ccccccccc}
\hline Ion & $\mathbf{N a}^{+}$ & $\mathbf{K}^{+}$ & $\mathbf{M g}^{2+}$ & $\mathbf{C a}^{2+}$ & $\mathbf{C l}^{-}$ & $\mathbf{H P O}_{4}{ }^{2-}$ & $\mathbf{S O}_{4}{ }^{2-}$ & $\mathbf{H C O}_{3}{ }^{-}$ \\
\hline Concentration (mmol/L) & 142 & 5.81 & 0.811 & 1.26 & 145 & 0.778 & 0.811 & 4.17 \\
\hline
\end{tabular}

\subsection{Implantation Procedure}

Animal Experimental Ethical Guidelines of Tsurumi University School of Dental Medicine (certificate No. 29A047) approved the animal study. Animal experiments were performed in accordance with the method of Raita et al. [44]. Briefly, the implants were inserted into the extracted socket of the maxillary first molar of the rat. The details were described below. Twenty-four Wistar rats (male, $180 \mathrm{~g}$ weight, 6 weeks old) were used. It is difficult to extract the tooth for older rats more than 6 weeks old. Rats were housed two per cage at 20 to $25^{\circ} \mathrm{C}$ in a $12 \mathrm{~h}$ circadian light rhythm and fed a powdered diet and tap water ad libitum during the experimental periods. Each animal received one implant. Twelve Ti and 12 MDF-Ti implants were divided into four groups of three each, namely, control Ti and control MDF-Ti, Acid Ti and Acid MDF-Ti, Alkali Ti and Alkali MDF-Ti, and Alkali-heat Ti and Alkali-heat MDF-Ti.

General anesthesia during the surgical interventions were conducted using an intraperitoneal injection of ketamine hydrochloride $\left(0.8 \mathrm{mg} / \mathrm{kg}\right.$, Ketalar ${ }^{\circledR}$ for Intramuscular Injection, Daiichi Sankyo Propharma Co.,Ltd., Tokyo, Japan) and medetomidine hydrochloride $\left(0.4 \mathrm{mg} / \mathrm{kg}\right.$, Domitor ${ }^{\circledR}$, Nippon Zenyaku Kogyo Co.,Ltd. Koriyama, Japan). The maxillary first molar on the right side was extracted using forceps. After an incision of the periodontal tissue, a dental reamer (\#90-\#150) enlarged the sockets of the mesial roots of the molar on the right side. The screw-type implant was inserted into the enlarged root socket using a screwdriver. Incised periodontal tissue were sutured by 7-0 polyamide nonresorbable sutures (BioFit-D, WASHIESU, Tokyo, Japan). After implantation surgery, benzyl penicillin $\mathrm{G}$ procaine $(3,000,000 \mathrm{U} / \mathrm{kg})$ was subcutaneously injected into the back of a rat and then atipamezole hydrochloride $(0.2 \mathrm{mg} / \mathrm{kg})$ was intraperitoneally injected to arouse a rat. Animals were euthanized by an overdose of carbon dioxide gas 6 weeks after implantation. Bone tissue block including implant material was dissected using a diamond band saw (Cutting Grinding System, BS-300CP band system, EXAKT, Apparatebau GmbH \& Co., KG, Norderstedt, Germany).

\subsection{Histological and Histomorphometrical Observations}

Fixation of dissected bone tissue block including the implants were carried out using $10 \%$ neutral buffered formalin for 7 days. They were then dehydrated through a graded series of ethanol $(70 \%, 80 \%, 90 \%, 96 \%$, and 100\%) and were embedded in methyl methacrylate resin. Methyl methacrylate resin was polymerized using bis(4-tert-butylcyclohxyl) peroxydicarbonate (PEROYL TCP, NOF Corp., Tokyo, Japan). Afterwards, non-decalcified sections were prepared using a cutting-grinding technique (Cutting Grinding System, BS-300CP band system \& 400CS microgrinding system, EXAKT, Apparatebau GmbH \& Co., KG, Norderstedt, Germany) [45]. The thickness of decalcified sections was approximately 50 to $70 \mu \mathrm{m}$. One or two sections were obtained from one implant. Non-decalcified sections were double stained with methylene blue and basic fuchsin. Bone responses were evaluated using a light microscope at a magnification of $200 \times(B X 51$, OLYMPUS, Tokyo, Japan). As histomorphometrical analysis, the percentage of bone-to-implant contact (BIC) was measured using an image analysis system (WinROOF, Visual System Division; Mitani Corporation, Tokyo, Japan). The region of interest (ROI) for the quantitative analysis of the BIC was determined as shown in Figure 2. The tip part of the implants was not evaluated. The BIC was defined as the percentage of the implant length of direct bone-to-implant contact to the length of the screw implant that was buried in bone in the ROI. 


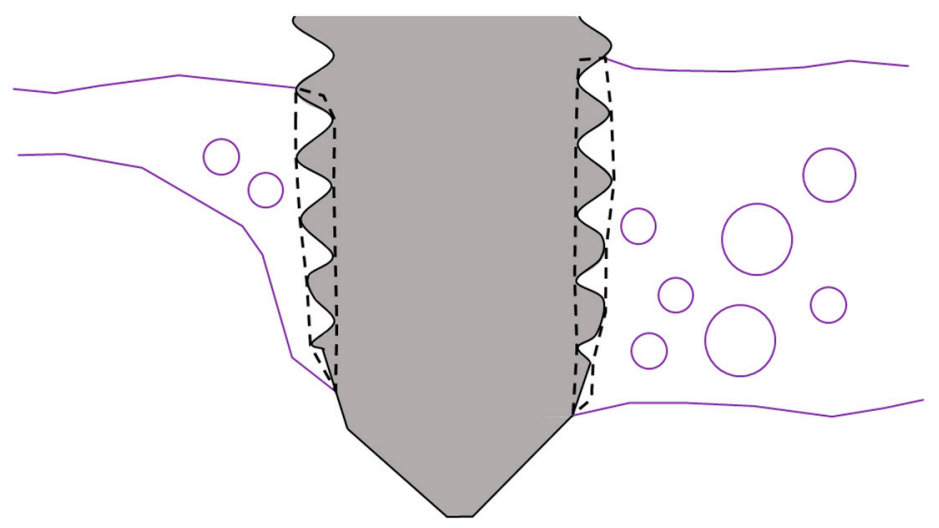

Figure 2. Region of interest (ROI) for the quantitative analysis of bone-to-implant contact (BIC).

\subsection{Statistical Analysis}

Data for surface roughness (Sa and Sdr), contact angles, and BIC data among each surface treatment were first analyzed by Kruskal-Wallis one-way analysis of variance (ANOVA). Because there were significant differences in Sa, Sdr, contact angles and BIC data, Tukey's post hoc test for multiple comparisons among means was performed. The unpaired t-test was used to compare data between Ti and MDF-Ti in Sa, Sdr, contact angles, and BICs. OriginPro 9.0 J (OriginLab Corp., Northampton, MA, USA) was used as a software for statistical analysis. P values of less than 0.05 were considered significant, and data were expressed as the mean \pm standard deviation (SD).

\section{Results}

Figures 3 and 4 show SEM images of the surfaces of Ti and MDF-Ti disks, and Figures 5 and 6 show SEM pictures of the surfaces of Ti and MDF-Ti screw-type implants after each surface treatment. Scratches by polishing were observed on the surfaces of the control Ti and MDF-Ti disks. For screw-type Ti and MDF-Ti implants, machined surfaces were identified.

Both disks and screw-type implants exhibited similar surface appearances after the same surface treatments. After Acid treatments, the dimples on the surface of Ti were rather irregularly orientated, and surfaces in the dimple were relatively flattened. On the contrary, a more complicated but more regular dimple structure was uniformly developed on the MDF-Ti surface. The presence of more minute nanoscale dimples in the microscale dimples on the MDF-Ti surface was confirmed (arrow). Fractal structures regularly and uniformly developed on the surface of MDF-Ti.

Alkali and Alkali-heat treatment produced totally different surface structures. A sponge-like porous surface was observed, pores with different sizes were randomly formed, and fiber structures were observed at the peripheries and inside the pores (arrowhead). No clear differences were observed between Ti and MDF-Ti.

Alkali-heat treatment produced submicron fiber network structures. As compared to Ti, finer and denser fiber network structures were recognized on MDF-Ti surfaces. The differences between the surfaces of Ti and MDF-Ti were more clearly recognized on screw-type implant surfaces. 

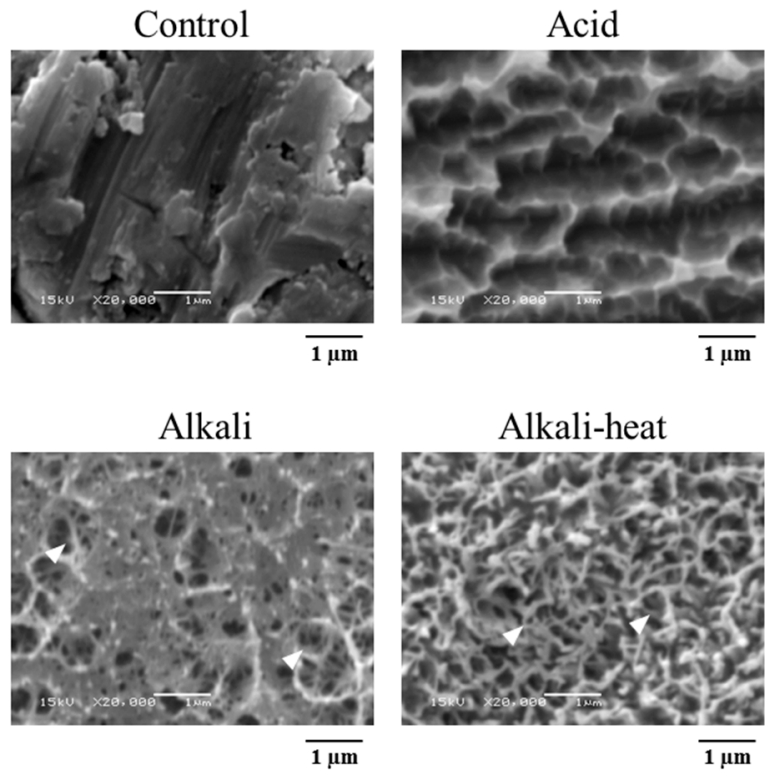

Figure 3. Scanning electron microscopy (SEM) images of the surface-treated Ti disks.
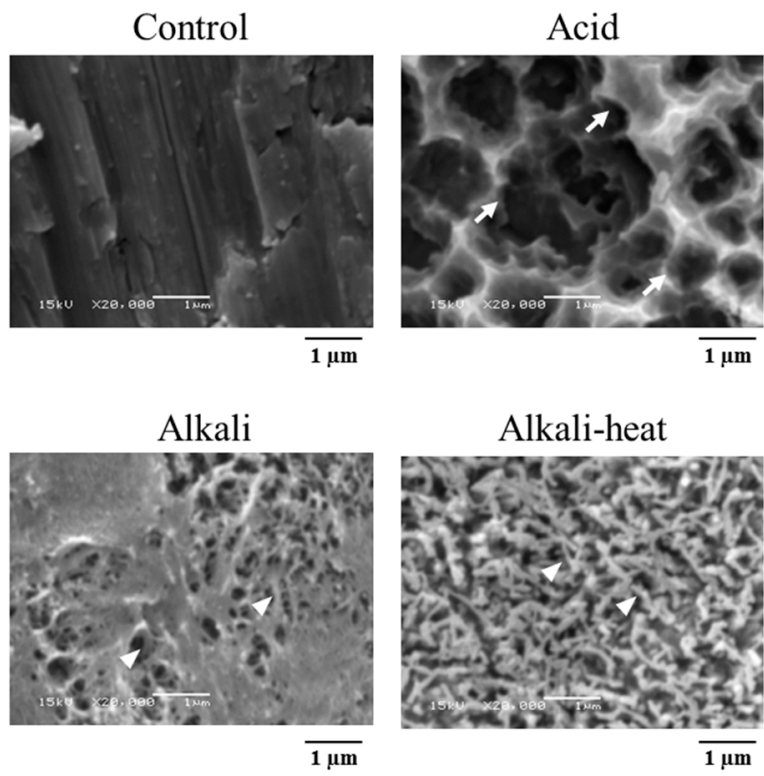

Figure 4. SEM images of the surface-treated MDF-Ti disks. 

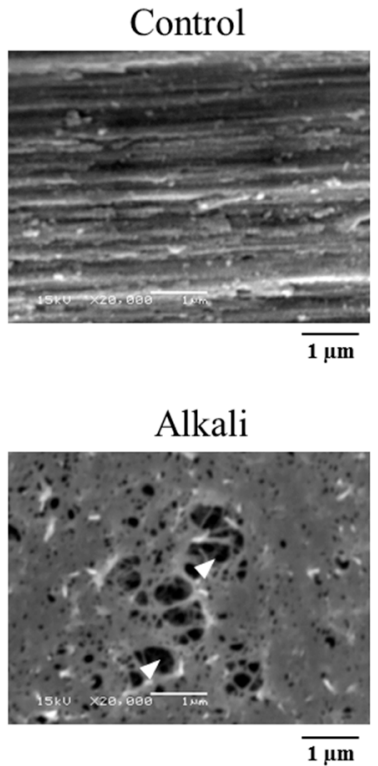

Acid

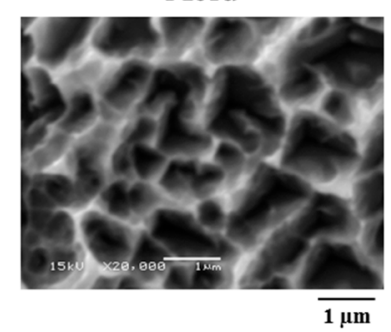

Alkali-heat

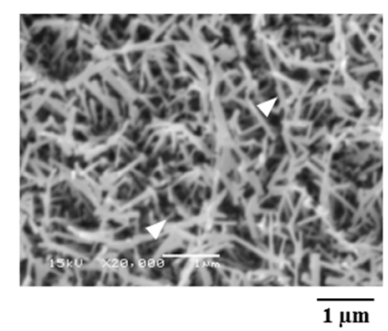

Figure 5. SEM images of the surface-treated Ti screw-type implants.
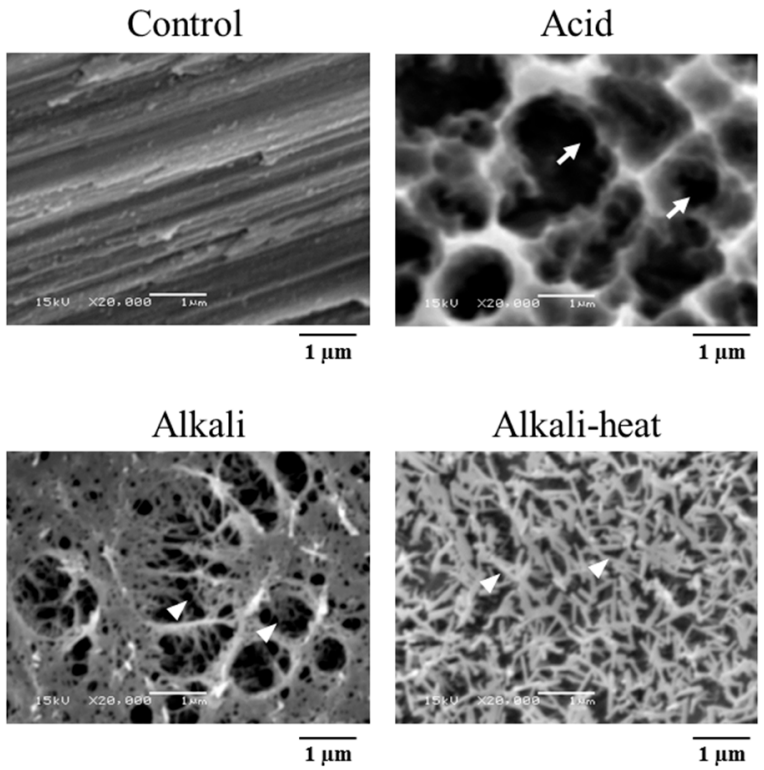

Figure 6. SEM images of the surface-treated MDF-Ti screw-type implants.

Tables 2 and 3 list the Sa and Sdr values for screw-type Ti and MDF-Ti implants after each surface treatment. Acid, Alkali, and Alkali-heat treatment produced significantly higher Sa than in the control $(p<0.05)$. There are significant differences in Sa between Acid and Alkali-heat for Ti $(p<0.05)$, but not for MDF-Ti $(p>0.05)$. A significant difference in Sa existed between Ti and MDF-Ti only for Acid treatment $(p<0.05)$. For Sdr, Acid treatment produced significantly greater Sdr than in the control, Alkali, and Alkali-heat $(p<0.05)$, and there were no significant differences among the control, Alkali, and Alkali-heat $(p>0.05)$. Ti and MDF-Ti showed the presence of significant difference after each surface treatment, except for the control $(p<0.05)$. 
Table 2. Three-dimensional arithmetic mean height (Sa) of surface-treated implants $(\mu \mathrm{m})$.

\begin{tabular}{ccccc}
\hline Implants & Control & Acid & Alkali & Alkali-Heat \\
\hline $\mathrm{Ti}$ & $0.27 \pm 0.02^{\mathrm{a}, \mathrm{A}}$ & $0.75 \pm 0.05^{\mathrm{b}, \mathrm{B}}$ & $0.56 \pm 0.06^{\mathrm{b}, \mathrm{c}, \mathrm{D}}$ & $0.42 \pm 0.12^{\mathrm{c}, \mathrm{E}}$ \\
$\mathrm{MDF}-\mathrm{Ti}$ & $0.29 \pm 0.08^{\mathrm{a}, \mathrm{A}}$ & $0.60 \pm 0.06^{\mathrm{b}, \mathrm{C}}$ & $0.48 \pm 0.06^{\mathrm{b}, \mathrm{c}, \mathrm{D}}$ & $0.47 \pm 0.12^{\mathrm{b}, \mathrm{E}}$ \\
\hline
\end{tabular}

$\pm:$ SD. Means with different superscripts are significantly different at $p<0.05$. Different small letters $(\mathrm{a}, \mathrm{b}, \mathrm{c})$ show significant differences among the four kinds of surface treatments with the same implants $(p<0.05)$. Different large letters (A, B, C, D, E) show significant differences between Ti and MDF-Ti with the same surface treatments $(p<0.05)$.

Table 3. Developed interfacial area ratio (surface deployment area rate) (Sdr) of surface-treated implants (\%).

\begin{tabular}{ccccc}
\hline Implants & Control & Acid & Alkali & Alkali-Heat \\
\hline $\mathrm{Ti}$ & $0.15 \pm 0.06^{\mathrm{a}, \mathrm{A}}$ & $4.72 \pm 0.51^{\mathrm{b}, \mathrm{B}}$ & $0.45 \pm 0.08^{\mathrm{a}, \mathrm{E}}$ & $0.39 \pm 0.03^{\mathrm{a}, \mathrm{G}}$ \\
$\mathrm{MDF}-\mathrm{Ti}$ & $0.14 \pm 0.10^{\mathrm{a}, \mathrm{A}}$ & $3.54 \pm 0.60^{\mathrm{b}, \mathrm{C}}$ & $0.30 \pm 0.02^{\mathrm{a}, \mathrm{F}}$ & $0.68 \pm 0.05^{\mathrm{a}, \mathrm{H}}$
\end{tabular}

$\pm:$ SD. Means with different superscripts are significantly different at $p<0.05$. Different small letters $(\mathrm{a}, \mathrm{b})$ show significant differences among the four kinds of surface treatments with the same implants $(p<0.05)$. Different large letters (A, B, C, E, F, G, H) show significant differences between Ti and MDF-Ti with the same surface treatments $(p<0.05)$.

Table 4 shows the results of the measurements of contact angles versus double-distilled water for $\mathrm{Ti}$ and MDF-Ti disks. Before surface treatment, there were no significant differences between Ti and MDF-Ti. After Acid, Alkali, and Alkali-heat treatment, contact angles were nearly equal zero for both Ti and MDF-Ti. Surface-treated Ti and MDF-Ti were superhydrophilic.

Table 4. Contact angles of surface-treated disks $\left(^{\circ}\right)$.

\begin{tabular}{ccccc}
\hline Implants & Control & Acid & Alkali & Alkali-Heat \\
\hline $\mathrm{Ti}$ & $59.9 \pm 1.5^{\mathrm{a}, \mathrm{A}}$ & $\fallingdotseq 0^{\mathrm{b}, \mathrm{B}}$ & $\fallingdotseq 0^{\mathrm{b}, \mathrm{C}}$ & $\fallingdotseq 0^{\mathrm{b}, \mathrm{D}}$ \\
$\mathrm{MDF}-\mathrm{Ti}$ & $54.5 \pm 2.6^{\mathrm{a}, \mathrm{A}}$ & $\fallingdotseq 0^{\mathrm{b}, \mathrm{B}}$ & $\fallingdotseq 0^{\mathrm{b}, \mathrm{C}}$ & $\fallingdotseq 0^{\mathrm{b}, \mathrm{D}}$ \\
\hline
\end{tabular}

$\pm:$ SD. Means with different superscripts are significantly different at $p<0.05$. Different small letters $(\mathrm{a}, \mathrm{b})$ show significant differences among the four kinds of surface treatments with the same implants $(p<0.05)$. Different large letters (A, B, C, D) show significant differences between Ti and MDF-Ti with the same surface treatments $(p<0.05)$.

Figures 7 and 8 show SEM observations of the surface appearances of Ti and MDF-Ti disks after 1 day of immersion in HBSS, respectively. The appearance of Ti and MDF-Ti surfaces were almost the same. Slight crystal depositions were observed on the control Ti and MDF-Ti. Greater amounts of crystal deposition were clearly observed on Acid-, Alkali-, and Alkali-heat-treated surfaces on Ti and MDF-Ti. It appeared that more crystals were deposited on the Acid-treated surfaces on Ti and MDF-Ti. Small crystals formed on Alkali-heated surfaces of Ti and MDF-Ti.

Figures 9 and 10 show the histological appearances of bone formation around the different implants at 6 weeks after implantation. No severe inflammatory responses were macroscopically observed in the tissues surrounding the implants, and failure or loosening of the implants did not occur during the preparation of histological samples. There were similar overall bone responses toward the different implants, and there were no distinct differences in bone response among the different surface-treated implants. It appeared that there was more bone formation around the tip of MDF-Ti implants as compared with Ti. More developed trabecular bone (asterisk) was observed around MDF-Ti implants for the Alkali-heat specimen. 


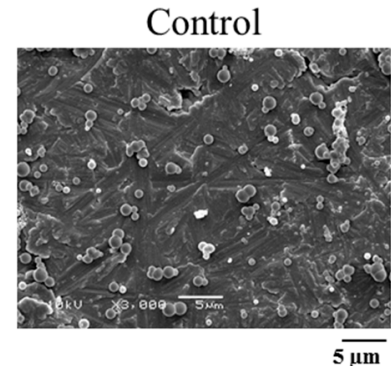

Alkali

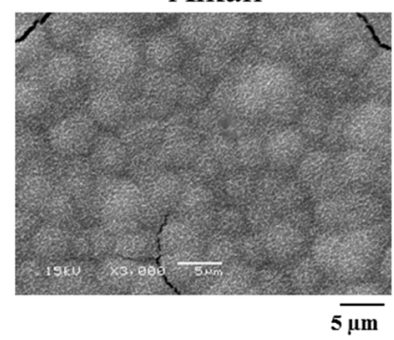

Acid

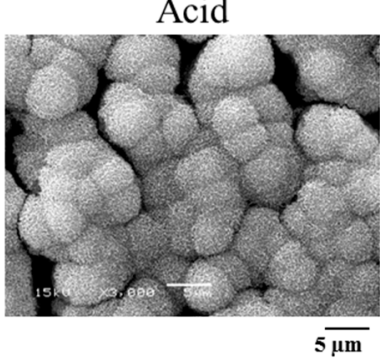

Alkali-heat

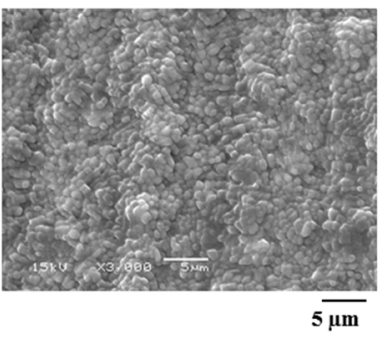

Figure 7. SEM pictures of the surface appearances of Ti disks after 1 day of HBSS immersion.
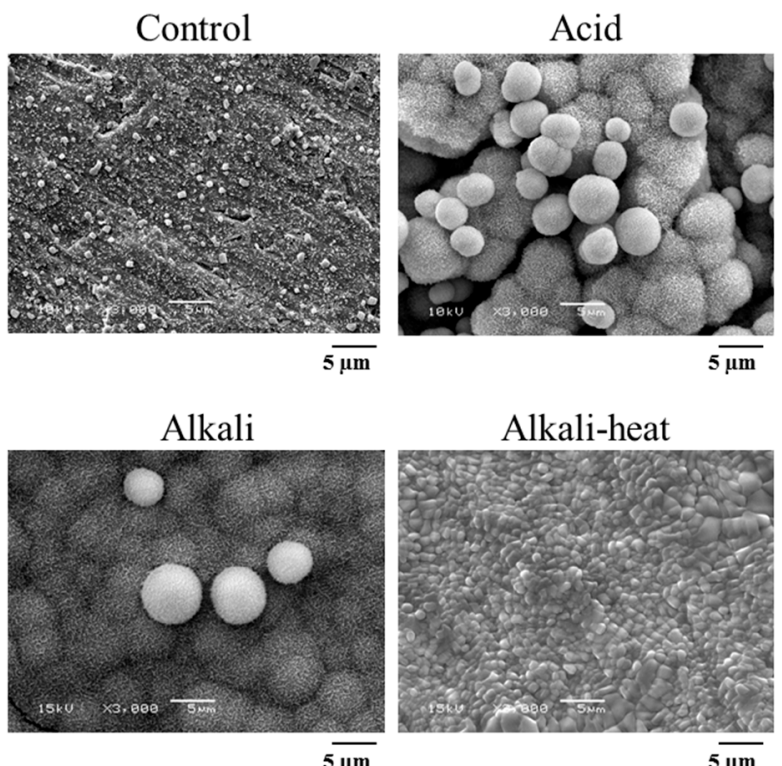

Alkali-heat

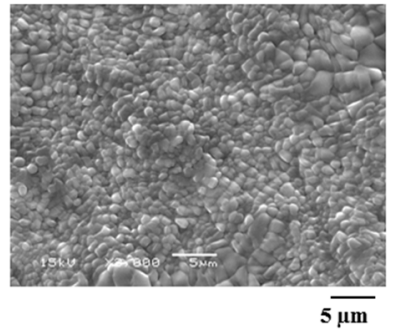

Figure 8. SEM pictures of the surface appearances of MDF-Ti disks after 1 day of HBSS immersion.

The results of BIC measurements are shown in Table 5. BIC values of Ti and MDF-Ti for Acid and Alkali-heat were significantly higher than those of the control $(p<0.05)$. There were no significant differences between the control and Alkali in Ti and MDF-Ti $(p>0.05)$. Acid and Alkali-heat treatment for MDF-Ti gave significantly greater BIC values than that for $\mathrm{Ti}(p<0.05)$. Control and Alkali specimens showed no significant differences in BIC between Ti and MDF-Ti $(p>0.05)$. 

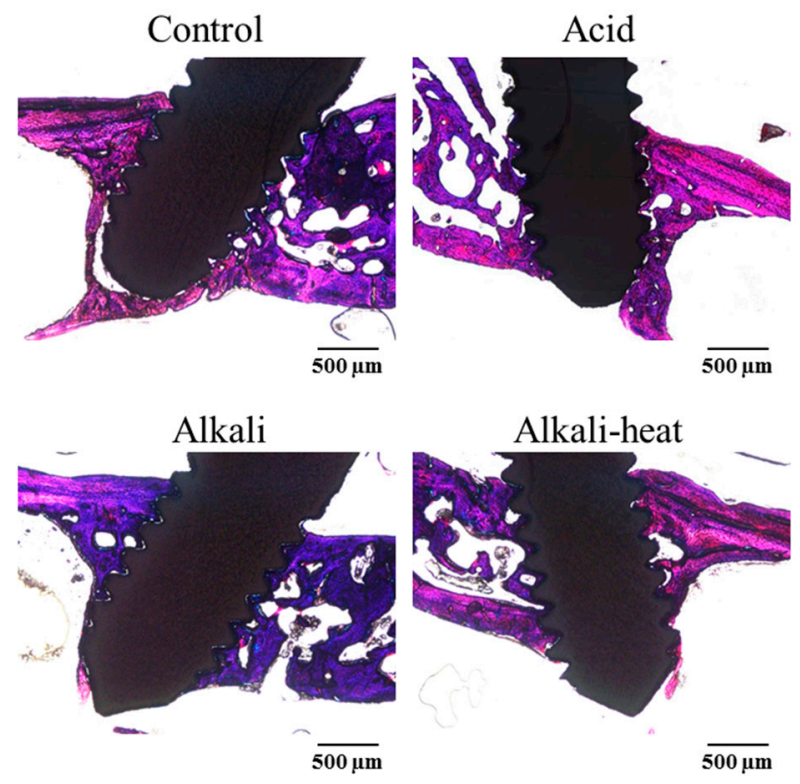

Figure 9. Histological appearances of bone formation around different Ti implants after 6 weeks of implantation.
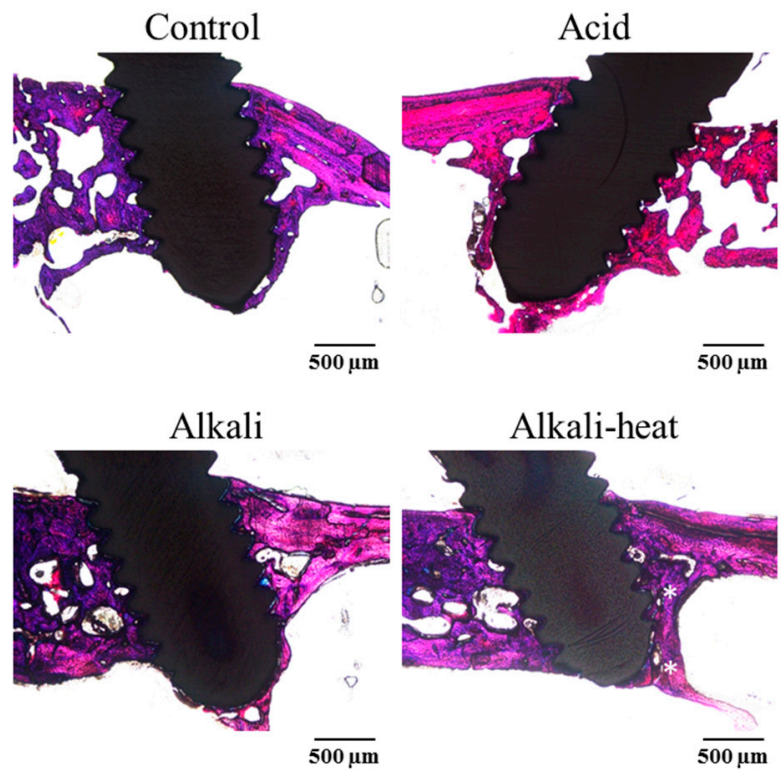

Figure 10. Histological appearances of bone formation around different MDF-Ti implants after 6 weeks of implantation.

Table 5. Percentage of the measured BIC (\%).

\begin{tabular}{ccccc}
\hline Implants & Control & Acid & Alkali & Alkali-Heat \\
\hline $\mathrm{Ti}$ & $55.8 \pm 2.3^{\mathrm{a}, \mathrm{A}}$ & $75.3 \pm 3.5^{\mathrm{b}, \mathrm{B}}$ & $68.9 \pm 9.5^{\mathrm{a}, \mathrm{b}, \mathrm{D}}$ & $75.9 \pm 2.5^{\mathrm{b}, \mathrm{E}}$ \\
$\mathrm{MDF}-\mathrm{Ti}$ & $65.8 \pm 10.4^{\mathrm{a}, \mathrm{A}}$ & $85.2 \pm 4.6^{\mathrm{b}, \mathrm{C}}$ & $75.5 \pm 6.5^{\mathrm{a}} \mathrm{b}, \mathrm{D}$ & $82.2 \pm 3.0^{\mathrm{b}, \mathrm{F}}$
\end{tabular}

\pm : SD. Means with different superscripts are significantly different at $p<0.05$. Different small letters $(\mathrm{a}, \mathrm{b})$ show significant differences among the four kinds of surface treatments with the same implants $(p<0.05)$. Different large letters (A, B, C, D, E, F) show significant differences between Ti and MDF-Ti with the same surface treatments $(p<0.05)$.

\section{Discussion}

In the present study, we evaluated the bone response toward surface-treated MDF-Ti as compared to that toward commercially pure Ti. The lower elastic modulus of MDF-Ti was an attractive 
property, as was its greater strength for a dental implant material. Previously, the bone response of an as-machined or sandblasted MDF-Ti implant was evaluated by implantation into the cortical bones of rabbit tibiae [36]. The bone responses were similar between MDF-Ti and Ti. Evaluation of surface modification towards bone response should be further investigated. Moreover, bone quality of cortical tibia bone is different from jaw bone. The evaluation after the implantation into the jaw bone should be needed for the application of MDF-Ti as a dental implant. In dental clinics, most of dental implants have a screw-type shape. Thus, we intended to implant surface modified screw-type implants into the extraction sockets of rat maxillary molars from a clinical perspective.

As surface treatments, Acid, Alkali, and Alkali-heat treatments were employed, revealing that both Acid and Alkali-heat treatments were effective methods for treating MDF-Ti surfaces for achieving better bone response. Acid treatments produced minute nanoscale dimples in the macroscale dimples for MDF-Ti. This was due to the ultrafine-grained structure of MDF-Ti. Our previous study revealed that fluoride corrosion progressed along ultrafine crystal grain boundaries for MDF-Ti [46]. Acid invasions will also proceed along the ultrafine crystal grain boundaries of MDF-Ti, similarly to fluoride corrosion. It is presumed that this unique structure with minute nanoscale dimples in the macroscale dimples produced better bone response toward MDF-Ti than toward Ti.

It is reported that the alkali treatment of Ti formed a sodium titanate hydrogel layer on the surface [41]. This hydrogel layer is easy to detach from Ti substrates. Subsequent heat treatment produced an amorphous sodium titanate layer that tightly bonded to Ti. It is presumed that the finer and denser fiber network structure was also due to the ultrafine-grained structure of MDF-Ti, and this surface structure was the reason for the better bone response of MDF-Ti.

SBF immersion experiments of Ti and MDF-Ti were employed as in vitro biocompatibility tests. Many studies have revealed that the ability of apatite crystal formation on the material in vitro commonly predicted the in vivo bioactivity of the materials [47]. Present SBF immersion experiment results suggest that Acid, Alkali, and Alkali-heat treatments cause better bone response than in the control. However, no significant differences in BIC values existed between the control and Alkali treatment for Ti and MDF-Ti implants. This was due to the weak and detachable titanate hydrogel on the surface without heat treatment, as mentioned above. The behaviors of crystal formation with Acid and Alkali-heat were different. More minute crystals were deposited on the Alkali-heat surfaces. The detailed mechanism for bone response toward Acid- and Alkali-heat-treated MDF-Ti should be further investigated by bone labeling or immunological analysis.

The surface roughness and wettability of the materials are other important factors that influence bone response $[1,33]$. Generally, a rough surface causes a better bone response. The present study evaluated the surface roughness of screw-type implants that were implanted into rat maxillae. The greater BIC values for Acid and Alkali-heat Ti and MDF-Ti were due to the rougher surfaces. However, there was no influence on BIC values for Alkali specimens in spite of rougher surfaces than those of the control. Besides surface parameters such as Sa and Sdr, differences in surface morphologies will influence the bone response [27].

Park et al. evaluated the osteoblast response to an ECAP-processed Ti [48]. The surfaces of ECAP-processed Ti were grit blasted with hydroxyapatite. They reported that the increased surface grain boundaries of the ultrafine-grained structure of the ECAP Ti provided a more optimal site for cell adhesion and accelerated subsequent osteoblast differentiation via microrough surface topographies. They concluded that this was due to the increase of wettability on grit-blasted microrough surfaces.

On the contrary, the present surface treatments produced superhydrophilic surfaces not only on MDF-Ti but also on Ti. Some methods for producing superhydrophilic titanium surfaces were reported, such as ultraviolet (UV) or oxygen-plasma [49-52]. Titanium implants with modified sandblasted/acid-etched surfaces, known as SLActive, also have superhydrophilic properties [53]. These superhydrophilic treatments are reported to show excellent bone formation and the enhancement of the initial attachment, as well as the proliferation and differentiation of osteoblast-like cells [50,52]. Superhydrophilicity by Acid and Alkali-heat treatment for Ti and MDF-Ti is one reason for their 
significantly greater BIC values. However, the BICs of Ti and MDF-Ti with Alkali treatment were not significantly greater than those of the controls $(p>0.05)$. Moreover, BICs of MDF-Ti were significantly higher than those of $\mathrm{Ti}$ in the case of Acid and Alkali-heat treatment, although both the surfaces of Ti and MDF-Ti were superhydrophilic. Other factors besides wettability influenced the bone response, as mentioned above. A detailed structure analysis of Acid and Alkali-heat surfaces of MDF-Ti should elucidate the bone-response mechanism.

Heat treatment of MDF-Ti is believed to increase the grain size of the ultrafine-grained structure and reduce the mechanical strength. The mechanical strength of both $\mathrm{Ti}$ and MDF-Ti will be reduced after heat treatment at $600{ }^{\circ} \mathrm{C}$ for $1 \mathrm{~h}$. The influence of heat treatment on mechanical strength or crystal grain size toward MDF-Ti will be studied further.

In the present study, we evaluated BIC for monitoring the bone response. Albrektsson et al. suggested that osseointegration corresponded to approximately $60 \%$ bone contact for titanium implant [54]. BICs of surface modified MDF-Ti exceeded this criterion. Besides BIC, other parameters such as removal torque should be needed for in vivo bone tissue response as a next series of our experiments.

\section{Conclusions}

Multi-directional forging pure Ti (MDF-Ti) with a higher ultimate tensile strength and lower elastic modulus is expected to be suitable as a dental implant material. Acid treatment to MDF-Ti produced minute nanoscale dimples in the microscale dimples to form regular fractal structures due to the ultrafine-grained structure. There were sponge-like porous networks after Alkali treatments and submicron fiber networks after Alkali-heat treatment on the surfaces of both Ti and MDF-Ti. Surface-treated specimens showed superhydrophilic surfaces. More crystal deposition was clearly observed on each surface-treated specimen after immersion in simulated body fluid for both $\mathrm{Ti}$ and MDF-Ti. Acid and Alkali-heat treatment for MDF-Ti caused better bone response than Ti. Surface modified MDF-Ti is a promising dental implant material. It is concluded that acid or Alkali-heat treated MDF-Ti has a possibility for the clinical application as a dental implant. MDF-Ti implant will be replaced for a current titanium implant.

Author Contributions: Conceptualization, G.S., T.H., H.M. and C.O.; methodology, G.S., M.H., M.Y. and T.H.; formal analysis, G.S. and N.H.; investigation, G.S., M.H., T.H and M.Y.; writing-original draft preparation, G.S. and T.H.; writing-review and editing, K.K., H.M. and C.O.; visualization, G.S., M.H. and N.H.; supervision, T.H. and C.O.; project administration, T.H.; funding acquisition, K.K., H.M., T.H. and C.O.

Funding: This research was partly funded by JSPS Grant-in-Aid for Scientific Research (B) (KAKENHI) Grant Number JP16H05525.

Acknowledgments: The authors are grateful to Kawamoto Heavy Industries Co., Ltd., for supplying multi-directionally forged titanium.

Conflicts of Interest: The authors declare no conflict of interest.

\section{References}

1. Wennerberg, A.; Albrektsson, T. On implant surfaces: A review of current knowledge and opinions. Int. J. Oral Maxillofac. Implant. 2009, 25, 63-74.

2. Domingo, J.L. Vanadium: A review of the reproductive and developmental toxicity. Reprod. Toxicol. 1996, 10, 175-182. [CrossRef]

3. Bondy, S.C. The neurotoxicity of environmental aluminum is still an issue. Neurotoxicology 2010, 31, 575-581. [CrossRef] [PubMed]

4. Long, M.; Rack, H.J. Titanium alloys in total joint replacement-A materials science perspective. Biomaterials 1998, 19, 1621-1639. [CrossRef]

5. Niinomi, M. Mechanical biocompatibilities of titanium alloys for biomedical applications. J. Mech. Behav. Biomed. Mater. 2008, 1, 30-42. [CrossRef] [PubMed] 
6. Santos, P.F.; Niinomi, M.; Cho, K.; Nakai, M.; Liu, H.; Ohtsu, N.; Hirano, M.; Ikeda, M.; Narushima, T. Microstructures, mechanical properties and cytotoxicity of low cost beta Ti-Mn alloys for biomedical applications. Acta Biomater. 2015, 26, 366-376. [CrossRef]

7. Stenlund, P.; Omar, O.; Brohede, U.; Norgren, S.; Norlindh, B.; Johansson, A.; Lausmaa, J.; Thomsen, P.; Palmquist, A. Bone response to a novel Ti-Ta-Nb-Zr alloy. Acta Biomater. 2015, 20, 165-175. [CrossRef]

8. Niinomi, M.; Hattori, T.; Morikawa, K.; Kasuga, T.; Suzuki, T.; Fukui, H.; Niwa, S. Development of low rigidity $\beta$-type titanium alloy for biomedical applications. Mater. Trans. 2002, 43, 2970-2977. [CrossRef]

9. Glassman, A.H.; Bobyn, J.D.; Tanzer, M. New femoral designs: Do they influence stress shielding? Clin. Orthop. 2006, 453, 64-74. [CrossRef]

10. Sumitomo, N.; Noritake, K.; Hattori, T.; Morikawa, K.; Niwa, S.; Sato, K.; Niinomi, M. Experiment study on fracture fixation with low rigidity titanium alloy: Plate fixation of tibia fracture model in rabbit. J. Mater. Sci. Mater. Med. 2008, 19, 1581-1586. [CrossRef]

11. Hao, Y.L.; Yang, R.; Niinomi, M.; Kuroda, D.; Zhou, Y.L.; Fukunaga, K.; Suzuki, A. Young's modulus and mechanical properties of Ti-29Nb-13Ta-4.6Zr in relation to $\alpha^{\prime \prime}$ martensite. Met. Mater. Trans. 2002, 33, 3137-3144. [CrossRef]

12. Majumdar, P.; Singh, S.B.; Chakraborty, M. Elastic modulus of biomedical titanium alloys by nano-indentation and ultrasonic techniques-A comparative study. Mater. Sci. Eng. A 2008, 489, 419-425. [CrossRef]

13. Niinomi, M.; Nakai, M. Titanium-Based Biomaterials for Preventing Stress Shielding between Implant Devices and Bone. Int. J. Biomate. 2011, 2011, 836587. [CrossRef] [PubMed]

14. Rack, H.J.; Qazi, J.I. Titanium alloys for biomedical applications. Mater. Sci. Eng. C 2006, 26, $1269-1277$. [CrossRef]

15. Pande, C.S.; Cooper, K.P. Nanomechanics of Hall-Petch relationship in nanocrystalline materials. Prog. Mater. Sci. 2009, 54, 689-706. [CrossRef]

16. Tsuji, N.; Ito, Y.; Saito, Y.; Minamino, Y. Strength and ductility of ultrafine grained aluminum and iron produced by ARB and annealing. Scr. Mater. 2002, 47, 893-899. [CrossRef]

17. Valiev, R.Z.; Maxim, M.Y.; Bobruk, E.V.; Raab, G.I. Grain refinement and mechanical behavior of the $\mathrm{Al}$ alloy, subjected to the new SPD technique. Mater. Trans. 2009, 50, 87-91. [CrossRef]

18. Furukawa, M.; Horita, Z.; Nemoto, M.; Valiev, R.Z.; Langdon, T.G. Microstructural characteristics of an ultrafine grain metal processed with equal-channel angular pressing. Mater. Charact. 1996, 37, 277-283. [CrossRef]

19. Miura, H.; Yu, G.; Yang, X. Multi-directional forging of AZ61Mg alloy under decreasing temperature conditions and improvement of its mechanical properties. Mater. Sci. Eng. A 2011, 528, 6981-6992. [CrossRef]

20. Miura, H.; Kobayashi, M. Development of ultrafine grained and high strength MDF pure titanium, Expected applications as biocompatible implants. Titan. Jpn. 2014, 62, 31-33.

21. Sabirov, I.; Valiev, R.Z.; Semenova, I.P.; Pippan, R. Effect of equal channel angular pressing on the fracture behavior of commercially pure titanium. Met. Mater. Trans. 2010, 41, 727-733. [CrossRef]

22. Serra, G.; Morais, L.; Elias, C.N.; Semenova, I.P.; Valiev, R.; Salimgareeva, G.; Pithon, M.; Lacerda, R. Nanostructured severe plastic deformation processed titanium for orthodontic mini-implants. Mater. Sci. Eng. C 2013, 33, 4197-4202. [CrossRef] [PubMed]

23. Zhilyaev, A.P.; Sergeev, S.N.; Popov, V.A.; Orlov, A.V. Evolution of Microstructure and microhardness in HPT titanium during annealing. Rev. Adv. Mater. Sci. 2014, 39, 15-19.

24. Miura, H.; Kobayashi, M.; Aoba, H.; Aoyama, H.; Benjanarasuth, T. An approach for room-temperature multi-directional forging of pure titanium for strengthening. Mater. Sci. Eng. A 2018, 731, 603-608. [CrossRef]

25. Hoshi, N.; Saita, M.; Kumasaka, T.; Banka, M.; Miura, H.; Kimoto, K. A new phase in the development of high strength pure titanium by Multi-Directional Forging. JJ Dent. Mater. 2013, 32, 403.

26. de Jonge, L.T.; Leeuwenburgh, S.C.; Wolke, J.G.; Jansen, J.A. Organic-inorganic surface modifications for titanium implant surfaces. Pharm. Res. 2008, 25, 2357-2369. [CrossRef] [PubMed]

27. Wennerberg, A.; Albrektsson, T. Effects of titanium surface topography on bone integration: A systematic review. Clin. Oral Implant. Res. 2009, 20, 172-184. [CrossRef]

28. Beutner, R.; Michael, J.; Schwenzer, B.; Scharnweber, D. Biological nano-functionalization of titanium-based biomaterial surfaces: A flexible toolbox. J. R. Soc. Interface 2010, 7, S93-S105. [CrossRef]

29. Hanawa, T. A comprehensive review of techniques for biofunctionalization of titanium. J. Periodontal Implant Sci. 2011, 41, 263-272. [CrossRef] 
30. Jemat, A.; Ghazali, M.J.; Razali, M.; Otsuka, Y. Surface Modifications and Their Effects on Titanium Dental Implants. Biomed. Res. Int. 2015, 2015, 791725. [CrossRef] [PubMed]

31. Buser, D.; Broggini, N.; Wieland, M.; Schenk, R.K.; Denzer, A.J.; Cochran, D.L.; Hoffmann, B.; Lussi, A.; Steinemann, S.G. Enhanced bone apposition to a chemically modified SLA titanium surface. J. Dent. Res. 2004, 83, 529-533. [CrossRef] [PubMed]

32. Chambrone, L.; Shibli, J.A.; Mercúrio, C.E.; Cardoso, B.; Preshaw, P.M. Efficacy of standard (SLA) and modified sandblasted and acid-etched (SLActive) dental implants in promoting immediate and/or early occlusal loading protocols: A systematic review of prospective studies. Clin. Oral Implants Res. 2015, 26, 359-370. [CrossRef] [PubMed]

33. Gittens, R.A.; Scheideler, L.; Rupp, F.; Hyzy, S.L.; Geis-Gerstorfer, J.; Schwartz, Z.; Boyan, B.D. A review on the wettability of dental implant surfaces II: Biological and clinical aspects. Acta Biomater. 2014, 10, 2907-2918. [CrossRef] [PubMed]

34. Zheng, C.Y.; Nie, F.L.; Zheng, Y.F.; Cheng, Y.; Wei, S.C.; Valiev, R.Z. Enhanced in vitro biocompatibility of ultrafine-grained titanium with hierarchical porous surface. Appl. Surf. Sci. 2011, 257, 5634-5640. [CrossRef]

35. Pippenger, B.E.; Rottmar, M.; Kopf, B.S.; Stübinger, S.; Dalla Torre, F.H.; Berner, S.; Maniura-Weber, K. Surface modification of ultrafine-grained titanium: Influence on mechanical properties, cytocompatibility, and osseointegration potential. Clin. Oral Implants Res. 2019, 30, 99-110. [CrossRef] [PubMed]

36. Suzuki, H.; Hirota, M.; Amemiya, T.; Ohkubo, C.; Hoshi, N.; Kimoto, K.; Hayakawa, T.; Miura, H. Cortical bone response of MDF titanium implant. J. Oral Tissue Eng. 2016, 13, 117-124.

37. Arai, Y.; Hoshi, N.; Kumasaka, T.; Hayakawa, T.; Ohkubo, C.; Kimoto, K. Development of optimal new titanium for dental implant material. J. Jpn. Soc. Oral Implant 2017, 30, 152.

38. Kim, H.M.; Miyaji, F.; Kokubo, T.; Nakamura, T. Effect of heat treatment on apatite-forming ability of Ti metal induced by alkali treatment. J. Mater. Sci. Mater. Med. 1997, 8, 341-347. [CrossRef] [PubMed]

39. Nishiguchi, S.; Fujibayashi, S.; Kim, H.M.; Kokubo, T.; Nakamura, T. Biology of alkali- and heat-treated titanium implants. J. Biomed. Mater. Res. A 2003, 67, 26-35. [CrossRef] [PubMed]

40. Tsukanaka, M.; Yamamoto, K.; Fujibayashi, S.; Pattanayak, D.K.; Matsushita, T.; Kokubo, T.; Matsuda, S.; Akiyama, H. Evaluation of bioactivity of alkali- and heat-treated titanium using fluorescent mouse osteoblasts. J. Bone Miner. Metab. 2014, 32, 660-670. [CrossRef] [PubMed]

41. Kokubo, T.; Yamaguchi, S. Growth of Novel Ceramic Layers on Metals via Chemical and Heat Treatments for Inducing Various Biological Functions. Front. Bioeng. Biotechnol. 2015, 3, 176. [CrossRef] [PubMed]

42. Wennerberg, A.; Albrektsson, T. Suggested Guidelines for the Topographic Evaluation of Implant Surfaces. Int. J. Oral Maxillofac. Implant. 2000, 15, 331-344. [PubMed]

43. Hanawa, T.; Ota, M. Calcium phosphate naturally formed on titanium in electrolyte solution. Biomaterials 1991, 12, 767-774. [CrossRef]

44. Raita, Y.; Komatsu, K.; Hayakawa, T. Pilot study of gingival connective tissue responses to 3-dimensional collagen nanofiber-coated dental implants. Dent. Mater. J. 2015, 34, 847-854. [CrossRef]

45. Donath, K.; Breuner, G. A method for study of undecalcified bones and teeth with attached soft tissues: The Sage-Schliff (sawing and grinding) technique. J. Oral Pathol. 1982, 11, 318-326. [CrossRef]

46. Suzuki, G.; Hoshi, N.; Kimoto, K.; Miura, H.; Hayakawa, T.; Ohkubo, C. Electrochemical property and corrosion behavior of multi-directionally forged titanium in fluoride solution. Dent. Mater. J.. in press.

47. Kokubo, T.; Takamada, H. How useful is SBF in predicting in vivo bone bioactivity? Biomaterials. 2006, 27, 2907-2915. [CrossRef]

48. Park, J.W.; Kim, Y.J.; Park, C.H.; Lee, D.H.; Ko, Y.G.; Jang, J.H.; Lee, C.S. Enhanced osteoblast response to an equal channel angular pressing-processed pure titanium substrate with microrough surface topography. Acta Biomater. 2009, 5, 3272-3280. [CrossRef]

49. Aita, H.; Hori, N.; Takeuchi, M.; Suzuki, T.; Yamada, M.; Anpo, M.; Ogawa, T. The effect of ultraviolet functionalization of titanium on integration with bone. Biomaterials 2009, 30, 1015-1025. [CrossRef]

50. Ogawa, T. Ultraviolet photofunctionalization of titanium implants. Int. J. Oral Maxillofac. Implant. 2014, 29, e95-e102. [CrossRef] [PubMed]

51. Eguro, T.; Murata, I.; Ohashi, I.; Maekawa, S.; Yoshinari, M. Influence of surface topography and surface chemical modification on hydrophilicity of titanium. J. Jpn. Soc. Oral Implant 2011, 24, 215-224. 
52. Yamamura, K.; Miura, T.; Kou, I.; Muramatsu, T.; Furusawa, M.; Yoshinari, M. Influence of various superhydrophilic treatments of titanium on the initial attachment, proliferation, and differentiation of osteoblast-like cells. Dent. Mater. J. 2015, 34, 120-127. [CrossRef] [PubMed]

53. Matsuzaki, H.; Yamamoto, H.; Shibata, K.; Komiyama, Y.; Yoshinari, M. Effect of atmospheric pressure plasma treatment on surface properties of commercial titanium implants. J. Jpn. Soc. Oral Implant 2014, 27, 528-540.

54. Albrektsson, T.; Eriksson, A.R.; Friberg, B.; Lekholm, U.; Lindahl, L.; Nevins, M.; Oikarinen, V.; Roos, J.; Sennerby, L.; Astrand, P. Histologic investigations on 33 retrieved Nobelpharma implants. Clin. Mater. 1993, 12, 1-9. [CrossRef]

(C) 2019 by the authors. Licensee MDPI, Basel, Switzerland. This article is an open access article distributed under the terms and conditions of the Creative Commons Attribution (CC BY) license (http:// creativecommons.org/licenses/by/4.0/). 